\title{
Autologous Fibular Strut Graft as a Substitute for Iliac Crest Graft and Bone Substitutes or Implant in Opening Wedge Valgus Tibia Osteotomy in Children
}

\author{
Dr. Nwachukwu AC, Dr. Nwachukwu CC
}

\begin{abstract}
Genu varum deformity in children remains a major worry for parents.

Children with pathologic genu varum deformities usually undergo corrective osteotomy to correct the deformity.

Several methods of osteotomy which include closing wedge lateral tibial osteotomy, dome osteotomy, opening wedge medial osteotomy have been employed.

Objective: Objective of the study was to determine the usefulness of autologous fibular strut graft as a substitute for other iliac crest graft, bone substitutes and implants as graft to fill the void and maintain the patency of the open wedge and correction.
\end{abstract}

Methods

Seventeen children underwent opening wedge osteotomy and the ipsilateral fibular strut was harvested to maintain patency of the open wedge and fill the void .

Result

15 of the 17 children had their deformities corrected with radiological union showing callus which incorporated the strong fibular strut in serial radiograghs.at 6weeks and 12weeks.

All expect 2 children bore full weight at 16 weeks with satisfactory correction of the deformity. One patient has deep infections and opted for another referral facility at 16 weeks.

\section{Conclusion:}

Autologous fibular strut graft is a very good if not a better graft for open wedge medial tibial osteotomy due to its strength, durability in maintaining correction, its cost effectiveness, the convenience of graft harvest and limited sites of wound and pain.

Index Terms - Autologous fibular strut, open wedge valgus tibia osetotomy.

\section{INTRODUCTION}

Several methods have been used in maintaining the open wedge of the medial tibia osteotomy in children.

Some of these include iliac crest graft, orthopaedic plates and screws and artifical bone substitutes.

These involve operations at parts distant from the site of surgery, causing another potential site of pain, discomfort, ugly scar and infection. Bone substitutes on the other hand are expensive and adds cost to a seemly simple procedure and an

Dr. Nwachukwu AC, Department of Surgery, Chukwuemeka Odumegwu Ojukwu University, Awka, Anambra State Nigeria.

Dr. Nwachukwu CC, Department of Community Medicine, Chukwuemeka Odumegwu Ojukwu University, Awka, Anambra State Nigeria. added burden in resource poor environment .

Using plates and screws will require another surgery for removal of implant.

This study aims at finding a better, cheap and more comfortable method of maintaining the open wedge of valgus tibial osteotomy for genu varum deformity without adding cost, ugly scar or a re-operation for removal of implant .

\section{METHODS}

A prospective study of 17 children with genu varum deformity was carried out between 2015 and 2018 in a tertiary orthopaedic center in Awka. All children presenting with genu varum deformities of tibia were recruited into the study and all those with genu valgum and other variants of knee deformity were excluded.

Informed consent was taken from their parents for proximal tibial medial opening wedge osteotomy.

The surgeries were carried out under general anaesthesia for those under 15 years of age and spinal anaesthesia for those above this age.

With patients supine and under appropriate anaesthesia, skin preparation and sterile drapings were done.

A vertical incision on the proximal aspect of lateral tibia was used to approach harvest the fibular at about $10 \mathrm{~cm}$ below the fibular neck.

A strut of about $3 \mathrm{~cm}$ to $5 \mathrm{~cm}$ was always harvested.

An elliptical incision on the medial aspect of the proximal tibial was used the approach the osteotomy.

A transverse cut parallel to the joint line was made.

This was opened until the deformity was over-corrected to about 10 degrees of valgus for children less than 12 years age with much grow still left and 7 degrees of valgus from older children. This also maintained the mechanical axis of the lower limb

The fibula strut was either placed tranversely into the cut or vertically depending of the size of the open wedge[Radiograph 1]

The wound was then closed polyglycolate sutures and skin staples,and the site of fibular harvest is also sutured after ensuring that more bone would not be needed.

This construct was then maintained by backslab which was completed as cast after few days.

The patients were followed up with radiogragh every 6 weeks for union. 


\section{Autologous Fibular Strut Graft as a Substitute for Iliac Crest Graft and Bone Substitutes or Implant in Opening Wedge Valgus Tibia Osteotomy in Children}

\section{RESULT}

The result below shows that there were more females $\{71 \%$ ] who had genu varum deformity than the male [29\%] showing a female to male ratio of 3.4:1.[Fig 1]. They were all pupils[59\%] and students[41\%][Fig 2]. Some of the children[31\%] have had a first operation from a centre before presenting while $61 \%$ are presenting for the first time[Fig 3].

The deformity occurred more on the left [63\%] than right [27\%][Fig 4]. Six of the children representing 35\% of all the children had bilateral deformities.

Following surgery, children below the ages of 12 years [63\%] had radiological union at 6weeks [Radiograph 1] [Fig 5] while those above 12 years of age representing $31 \%$ of the children had radiological union at 12 weeks [Radiograph 3][Fig 6].

One patient's union was delayed due to serious infection. The younger age group commenced ambulation in cast at 6 weeks[Fig 7] while the older age group ambulated averagely at 12 weeks[Fig 8].
Most[88\%] have commence full weight bearing ambulation [Picture 1] at 16weeks while an obese patient[6\%] was still placed on partial weight bearing and the patient with infection not allowed to ambulate[Fig 9].

Parents of the patients and the patients who could appreciate their former deformities were satisfied with the outcome.

2 patients representing $12 \%$ of all the patients had recurrence of their deformities and are awaiting surgery.

and came with recurrence while Out of the 17 children [23 deformities] who had this surgery, 15 children with 20 tibia vara had very good callus formation at 12 weeks. 10 children below the ages of 12 had good callus at 6weeks

The fibular strut has gotten well incorporated in the callus while maintaining the size of the wedge.

We allowed partial weight bearing at 10 weeks and full weight bearing at 14 weeks of for children below the age of 12 years not obese.

Full weight bearing was allowed at 16 to 18 weeks for older children from the ages of 12 to 17 years and obese children.

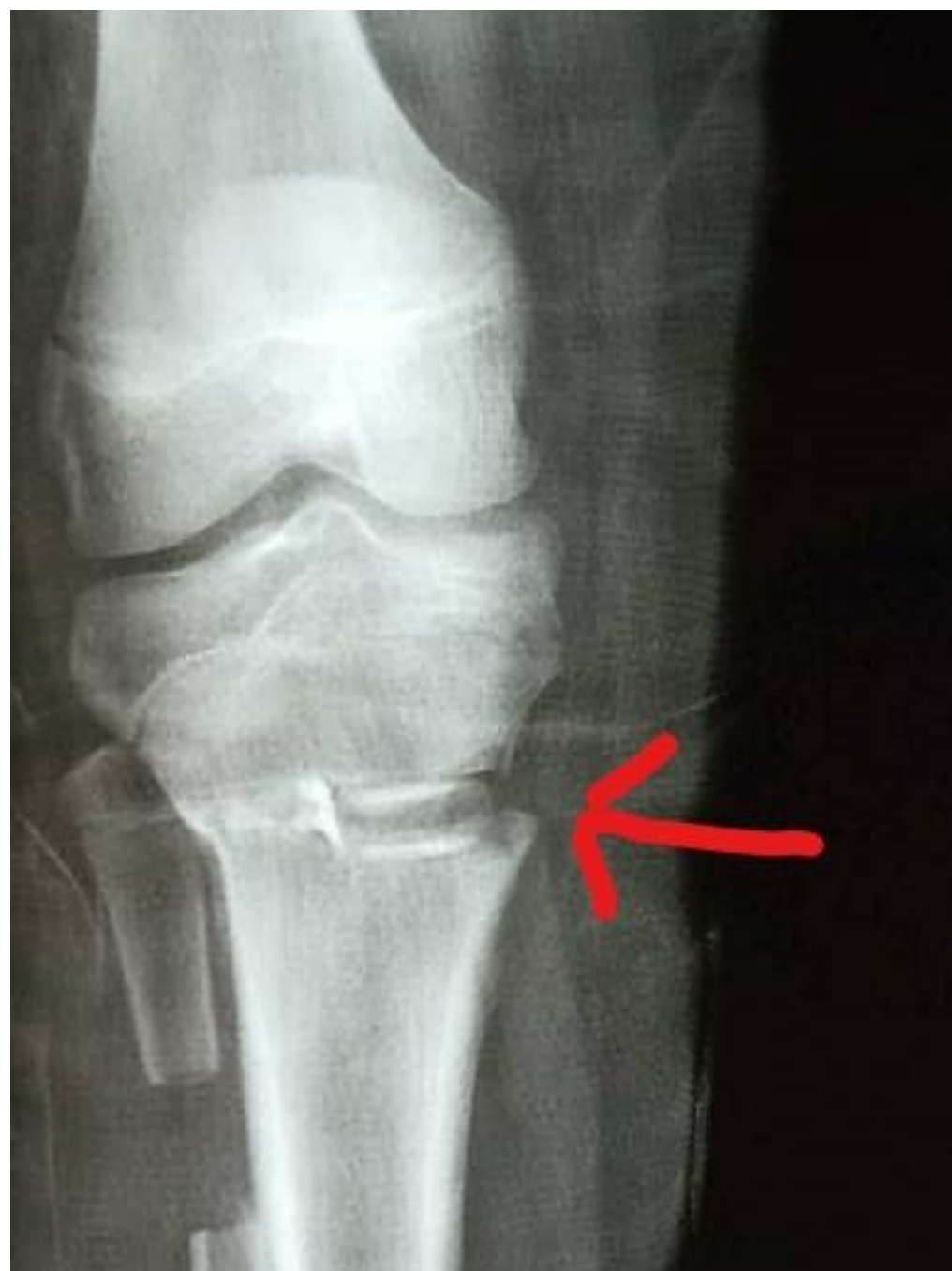

Radiograph 1 : Incooperated Autologous Fibula Strut Graft in-situ maintaining the open wedge 


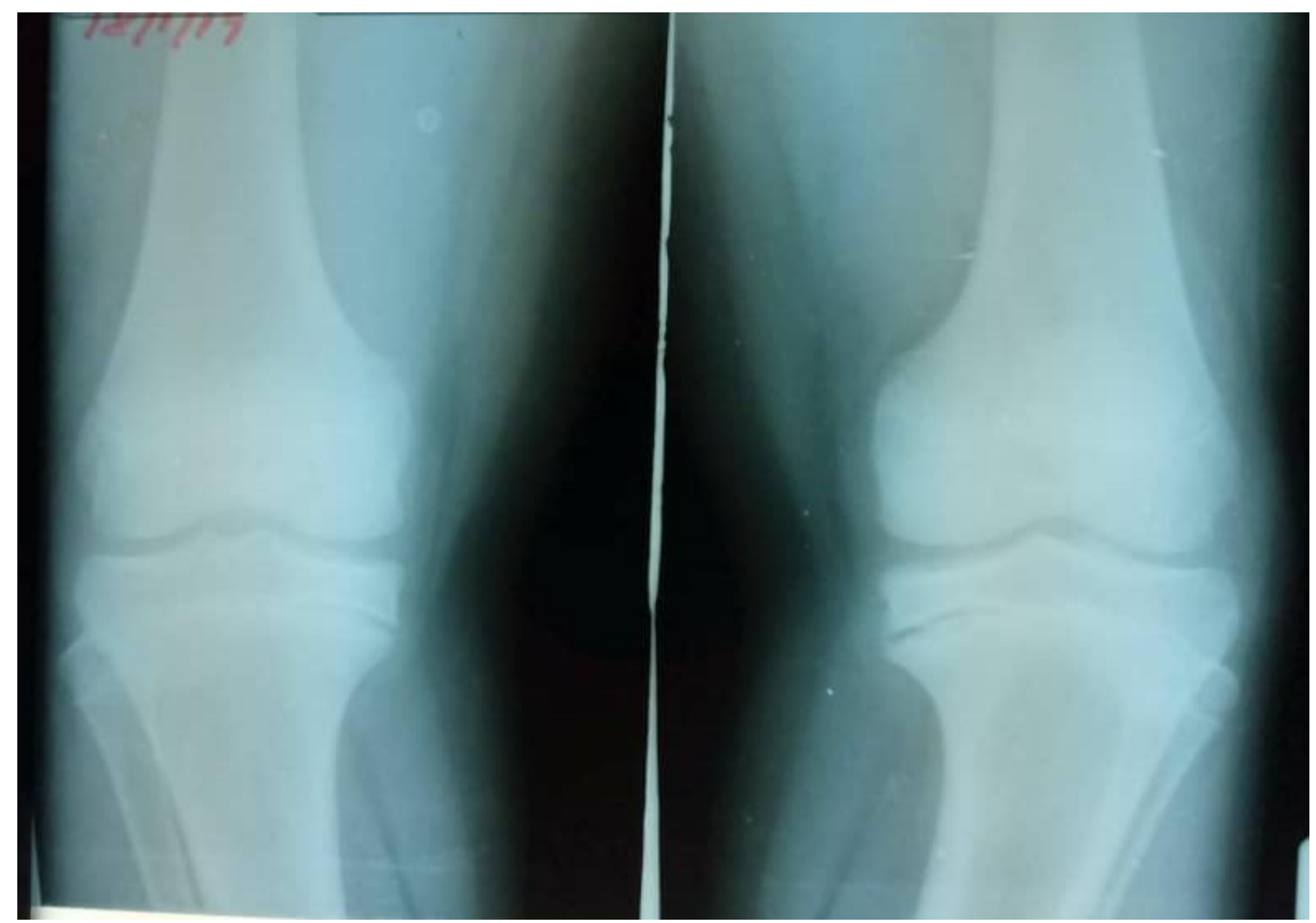

Radiograph 2: Pre-op radiograph.

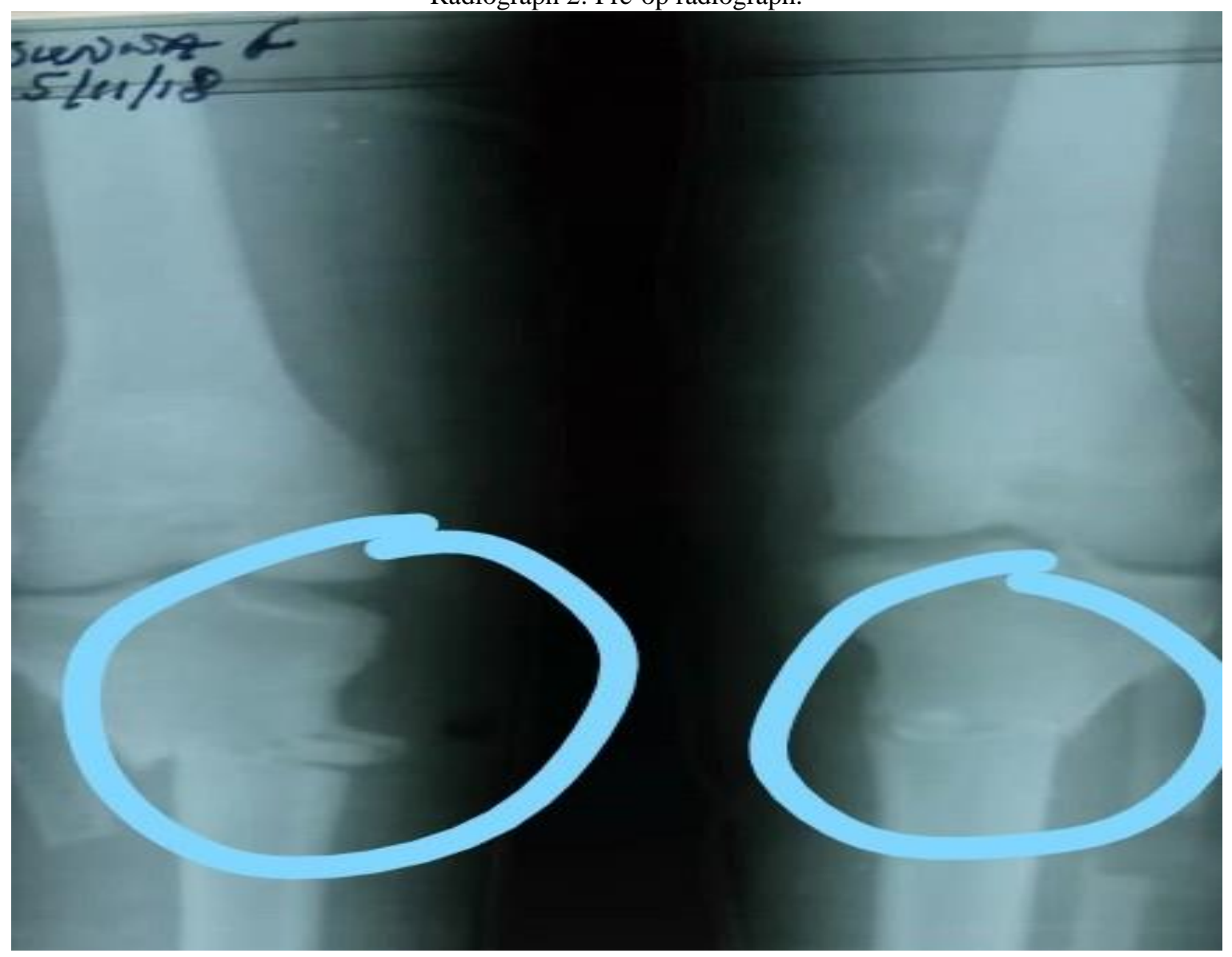

POST-OP RADIOGRAPH 3: Inco-operated autologous fibular strut AP. VIEW 
Autologous Fibular Strut Graft as a Substitute for Iliac Crest Graft and Bone Substitutes or Implant in Opening Wedge Valgus Tibia Osteotomy in Children

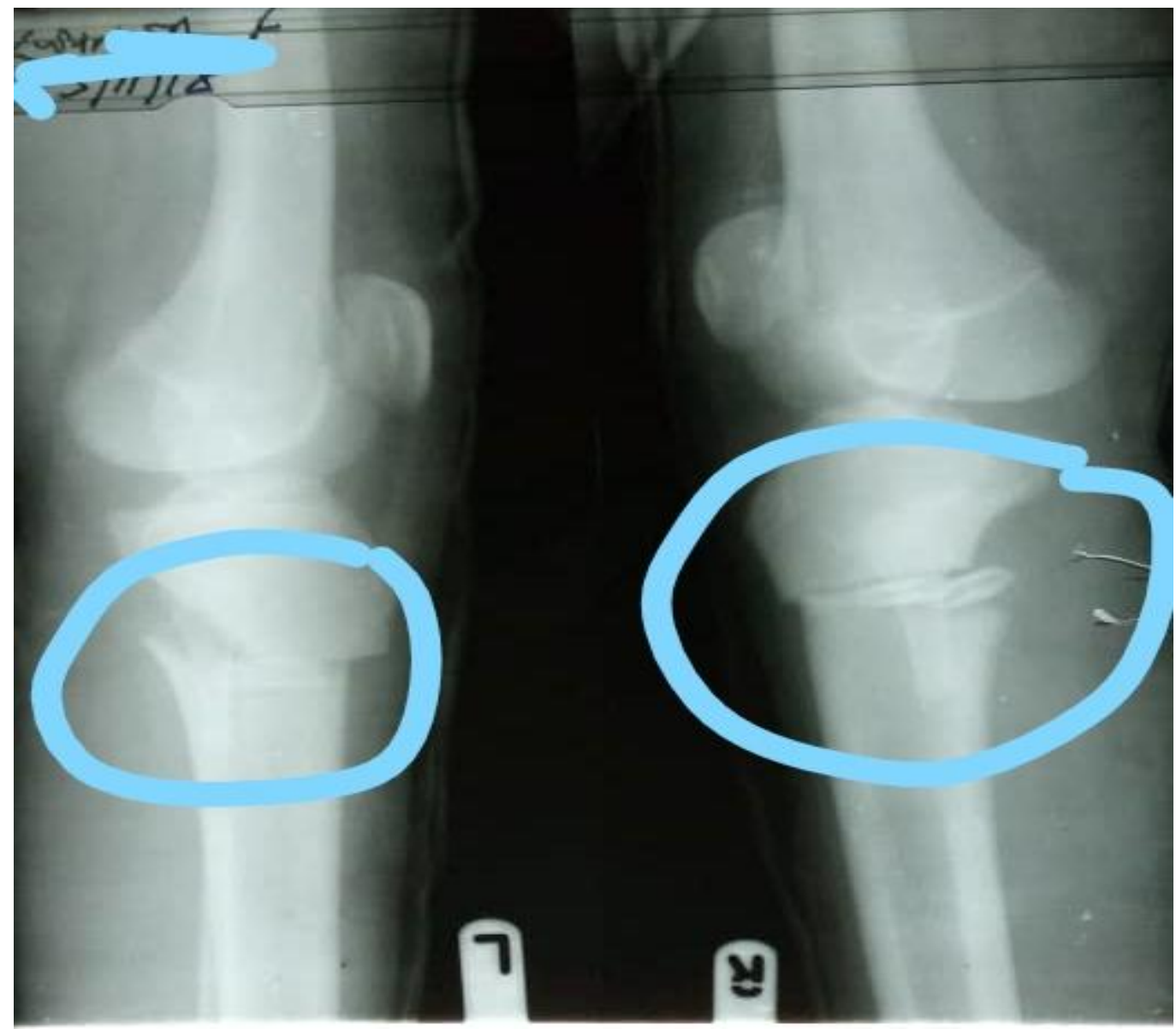

POST-OP RADIOGRAPH 3: Inco-operated autologous fibular strut LATERAL VIEW

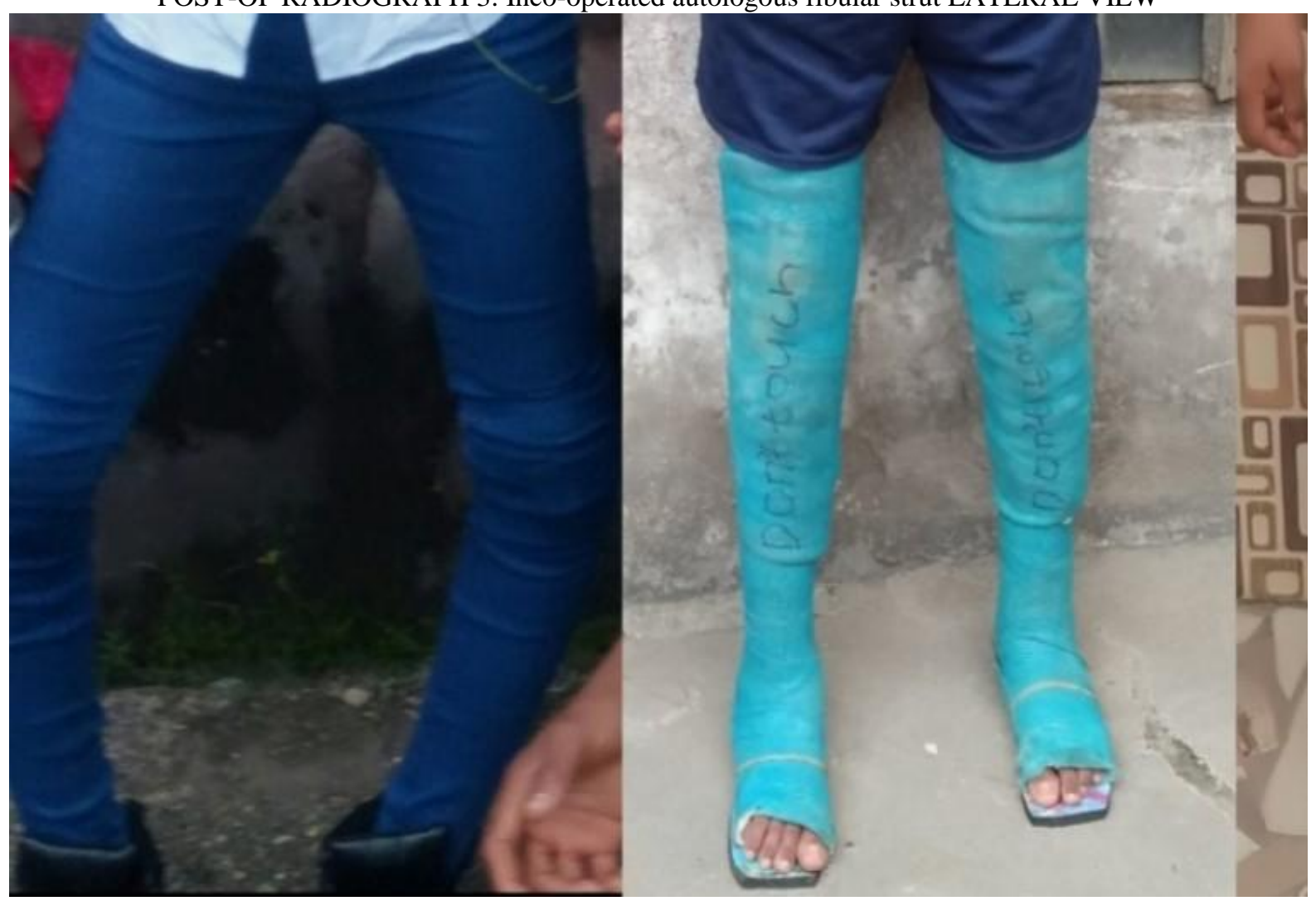

PICTURE 2: SHOWING PRE-OP, IMMEDIATE POST-OP 


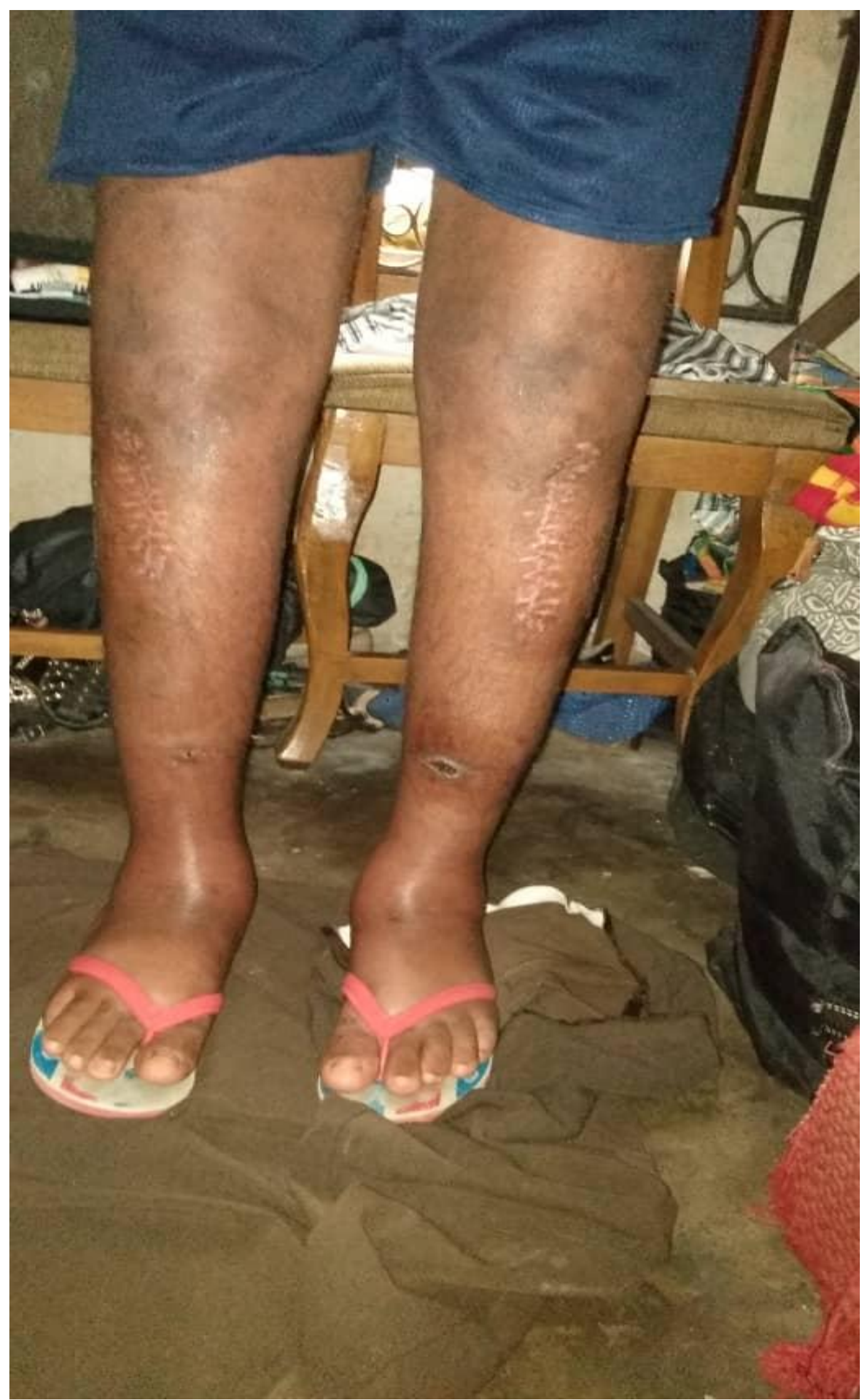

PICTURE 3: POST-OP LOOKS OF THE LIMBS AND FULL WEIGHT BEARING PERIOD. 
IV. RESULT

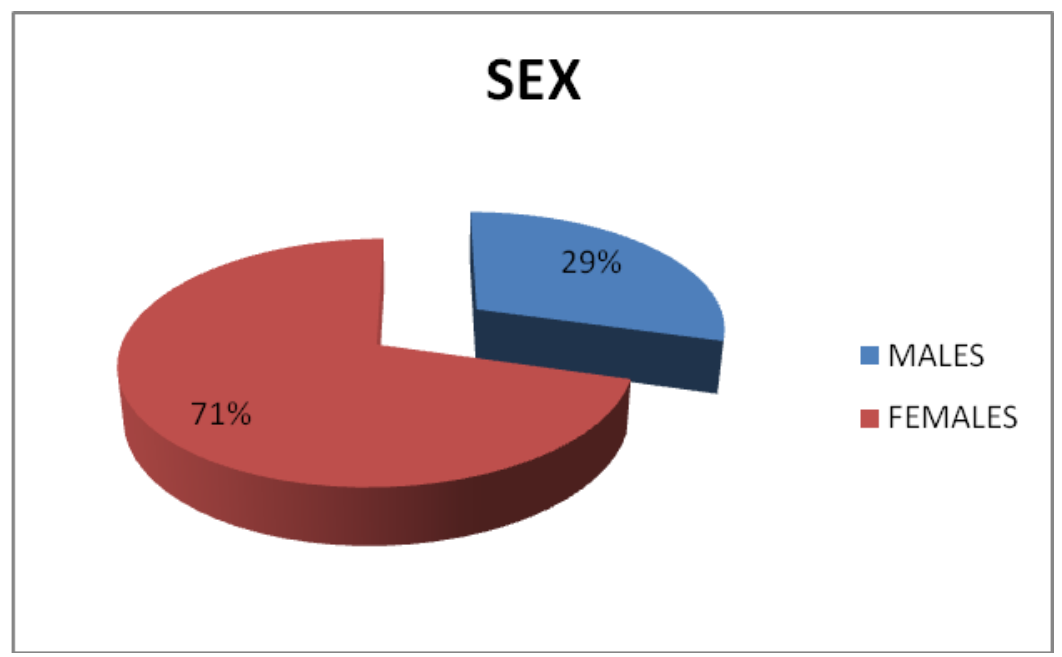

FIG 1 : SEX OF PATIENTS

\section{OCCUPATION}

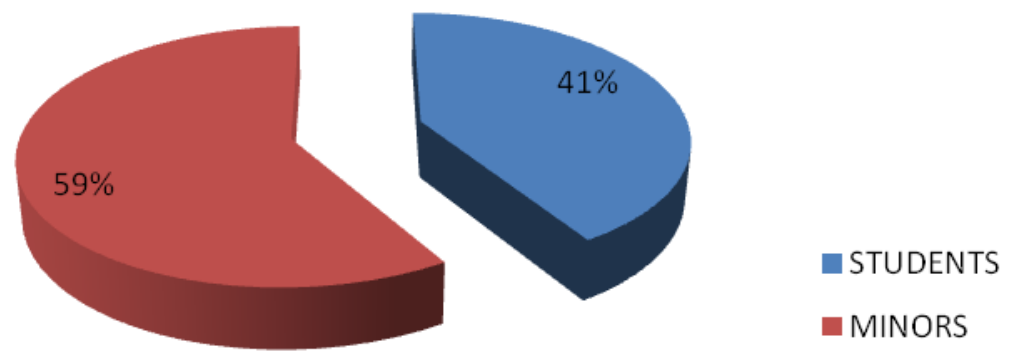

FIG 2: OCCUPATION OF PATIENTS

IS THE FIRST OR SECOND OPERATION

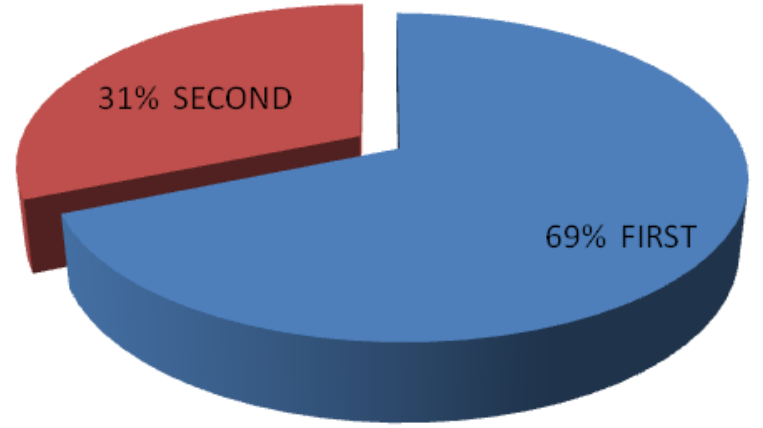

FIG 3: NUMBER OF OPERATIONS 


\section{IF ON ONE LEG, WHICH SIDE}

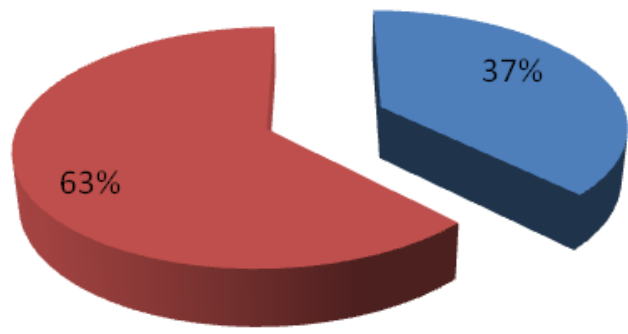

\section{RADIOLOGICAL UNION AT 6 weeks.}

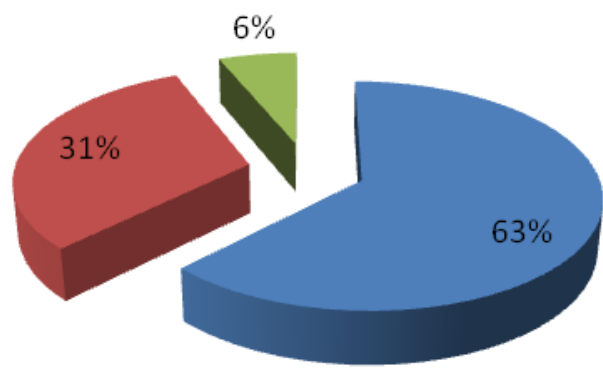

- UNION

- INCOMPLETE UNION

DELAYED

FIG 5 : UNION AT 6 WEEKS

\section{RADIOLOGICAL UNION AT 12weeks}

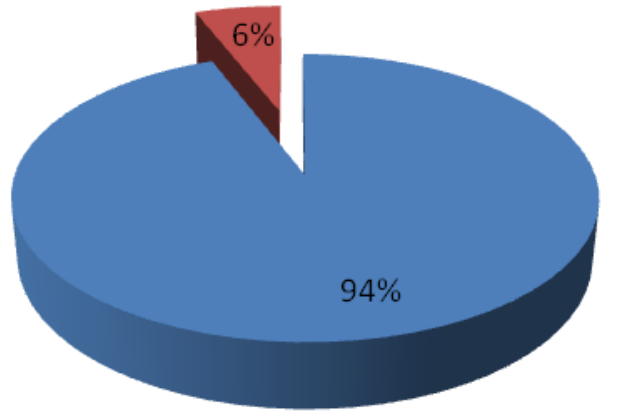

- UNION

DELAYED

FIG 6: UNION AT 12 WEEKS 


\section{Ambulation at 6 weeks}

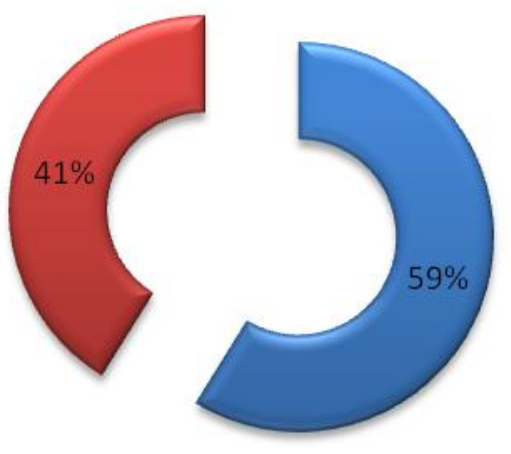

$\square$ yes with aid

no ambulation

FIG 7: AMBULATION AT 6 WEEKS

\section{Ambulation at 12 weeks}

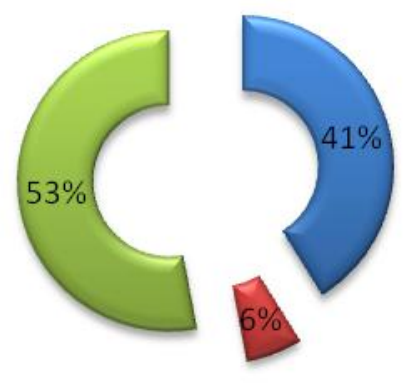

$\square$ yes with aid

$\square$ no ambulation

$\square$ yes without aid

FIG 8: AMBULATION AT 12 WEEKS

\section{Ambulation at 16 weeks}

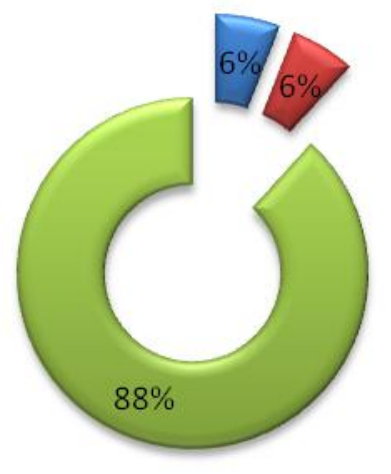

yes with aid

no ambulation

$\square$ yes without aid

FIG 10: AMBULATION AT 16WEEKS 


\section{Parents satisfaction with outcome}

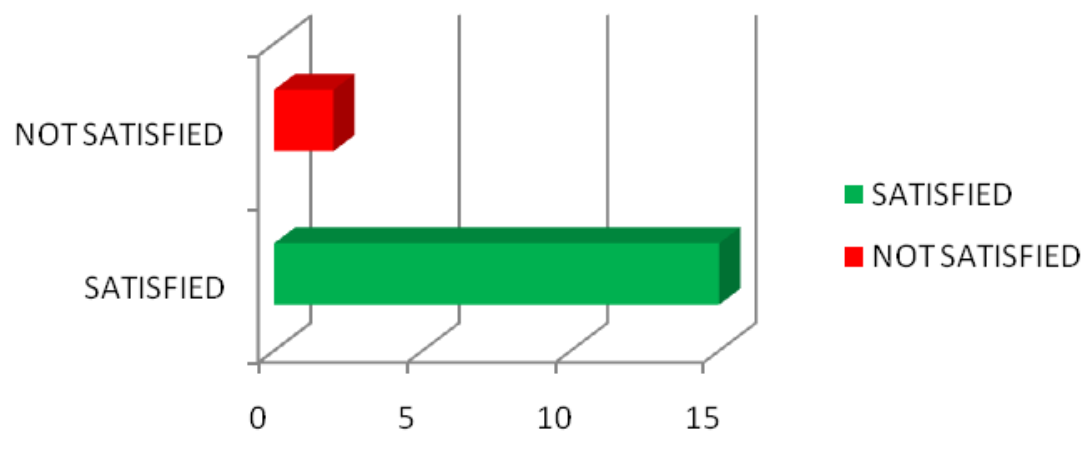

FIG 11: PARENTS/PATIENTS’ SAITISFACTION

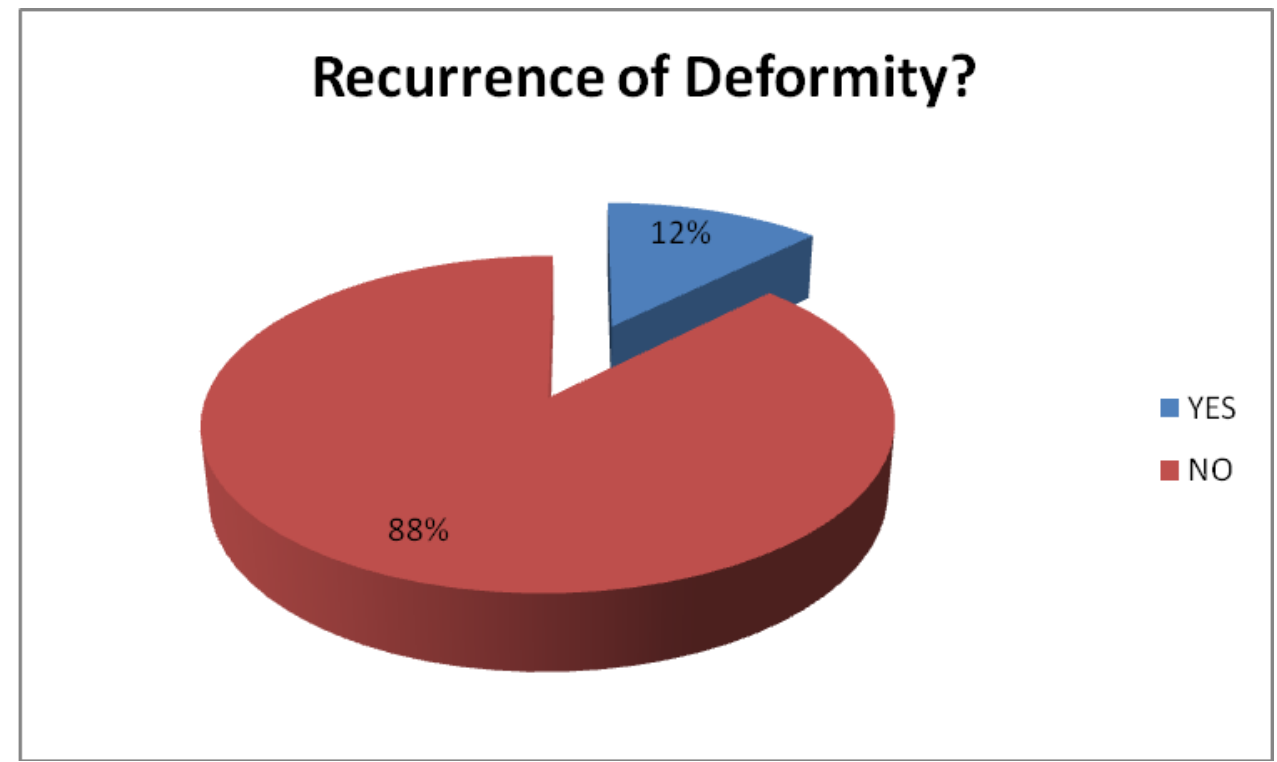

FIG 12: RECURRENCE OF DEFORMITY

The left leg was more affected (63\%) than the right (37\%). Fibula osteotomy was below $10 \mathrm{~cm}$ below the fibula neck.

\section{DISCUSSION}

Angular deformities usually occur in children. Genu varum deformity in children is normal between the ages of 0 to 2 years. It is usually of of beningn origin[1]. Idiopathic tibia vara is the most common cause of pathological bowing in children[2]. Those of metabolic origin are corrected with medications. Persistent deformities are safely managed by corrective osteotomy. Different clinicians use different methods for correction of genu varum deformity which include but not limited to closing wedge valgus osteotomy, dome osteotomy and opening wedge valgus osteotomy. We examined another method of maintaining an opening wedge osteotomy and got interesting result.

In this study, we had a female to male preponderance. There were twelve females to 5 males representing $71 \%$ and $29 \%$ respectively of children presenting with genu varum deformities[Fig 1]. This is similar to findings by some others scholars showing that genu varum deformity occurs more in the females than in the males[1] [3]. Sixty-nine percent of the children were presenting for the first time while $31 \%$ have had surgery done in another hospital and presenting with recurrence.
This is contrary to what was advocated by Ogbenudia et al who argued that there peroneal nerve damage occurs more with proximal fibular osteotomy than distal[5]. No peroneal nerve damage was experienced in this study. I am of the opion that when one gives a gap of $10 \mathrm{~cm}$ below the fibular neck before the fibular osteotomy, he is mostlikey to avoid damaging the common peroneal nerve which wraps round the fibular neck on its pathway to the leg.

Several authors use different methods to maintain their osteotomy. These range from use of porous hydroxyappetite[11] to use of internal fixators alone[12]. Pierre-Louis et al used allografts in his several osteotomies. His reason ranges from limited surgical sites, reduced operation time and reduced post operative pain and prevention of complications of harvesting autogenous grafts , however, he did recognise that autogenous grafts remain gold standard[8]. His fears about complications of fibular harvest which includes distal migration of the fibular head, talar tilt, proximal migration of the lateral malleolus and diaphyseal tibial valgus have not been experienced by after 3years of observing some of these my patients.

Children below the ages of 12 years had radiological union at 6 weeks after the surgery and were able to have protected weight bearing[Fig5][Fig 7], while those above 12 years had 


\section{Autologous Fibular Strut Graft as a Substitute for Iliac Crest Graft and Bone Substitutes or Implant in Opening Wedge Valgus Tibia Osteotomy in Children}

an average radiological union at 12 weeks and also commenced weight bearing same period [Fig 6][Fig 9]. All were able to ambulate fully at 16 weeks[Fig 10]. Radiographs obtained show clearly how the fibular(still very visible in outline) was incorporated in the opening wedge[Radiograph 1].This not only maintained the open wedge but also withstood ambulation load[8]. This pattern of healing is consistent with the calculation of Selvadurai Nayagam et al in Apley's system of Orthopaedics[15] .Ninety-two percent of parents and patients were satisfied with the outcome of the cases. Only $6 \%$ were dissatisfied due to infection, delayed union and delayed ambulation which occurred in their own case[Fig 11].These complications are known and documented[11][13].

There was recurrence of $12 \%$ of the cases after following them up to 3years. The parents were duly counselled during the surgery that this recurrence could occur and therefore were not surprised about the recurrence. These ones will have a re-operation.

\section{CONCLUSION}

Autologous fibular strut graft is a very good if not a better graft for open wedge medial tibial osteotomy due to its strength, durability in maintaining correction, its cost effectiveness, the convenience of graft harvest, and limited sites of wound and pain. It is easily accepted by both literate and not so literate parents without the resentment or psychology of using another person's bone or an artificial material.

\section{REFERENCES}

[1] Brooks, Werner C. MD; Gross, Richard H. MD Genu Varum in Children: Diagnosis and Treatment, Journal of the American Academy of Orthopaedic Surgeons: November-December 1995 - Volume 3 Issue 6 - p 326-335

[2] Ramin Espandar, MD, Seved Mohammad-Javad Mortazavi, MD, and Taghi Baghdadi, MD Angular Deformities of the Lower Limb in Children Asian J Sports Med. 2010 Mar; 1(1): 46-53.

[3] A. H. Bakhtiary, F. Elham, A. Rezasoltani, Effects of Genu Varum Deformity on Postural Stability, Int J Sports Med 2012; 33(06): $469-473$

DOI: $10.1055 / \mathrm{s}-0031-1301331$

[4] Eric M. Bateson, Non-rachitic bow leg and knock-knee deformities in young Jamaican children 1966, Br. J. Radiol., 39, 92-101

[5] A.O Ogbenudia, P.F.A Umedese, A Bafor, E Igbinovia, P.E Ogbenudia, The level of fibula osteotomy and incidence of peroneal nerve palsy in proximal tibial osteotomy Journal of Surgical Technique and Case Report, Vol 2, No 1 (2010)Pgs 8-10, http://dx.doi.org/10.4103/2006-8808.63709

[6] 6] P. Putzeys, P. Wilmes, M Merle,Triple tibial osteotomy for the correction of severe bilateral varus deformity in a patient with late-onset Blount's disease Knee Surgery, Sports Traumatology, ArthroscopyMarch 2013, Volume 21, Issue 3, pp 731-735,

[7] Vincent.P. Novak, Open wedge osteotomy system and surgicalmethod, US patent 8,083,746,2011

[8] Pierre-Louis DOCQUIER, Laurent PAUL, Maryline MOUSNY, Olivier CORNU, Christian DELLOYE,The use of allografts in paediatric orthopaedic surgery, Acta Orthop. Belg. , 2007, 73, 551-557

[9] Scheffer, M M; Peterson, H A, Opening-wedge osteotomy for angular deformities of long bones in children, JBJS: Mar 1994 - Volume 76 Issue 3 - p 325-334

[10] J. Soleimanpour, A. Elmi, M.A. Jafari and M. Goldust, Comparison of Genu Varum Treating Results Using Open and Closed Wedge High Tibial Osteotomy, Pakistan Journal of Biological Sciences, 16: 686-691.

[11] Koshino, Tomihisa, MD, PhD; Murase, Tomoo, MD, PhD; Saito, Tomoyuki, MD, PhDMedial Opening-Wedge High Tibial Osteotomy with Use of Porous Hydroxyapatite to Treat Medial Compartment Osteoarthritis of the KneeJBJS: January 2003 - Volume 85 - Issue 1 - p 78-85

[12] Alex E. Staubli, Carlo De Simoni, Reto Babst, Philipp Lobenhoffer, TomoFix: a new LCP-concept for open wedge osteotomy of the medial proximal tibia - early results in 92 cases, Injury 2003, Vol. 34, Suppl. 2 ,

[13] Nikolaus Reischl, Peter Wahl,Matthias Jacobi,Steve Clerc Emanuel Gautier, Roland P. Jakob,Infections after high tibial open wedge osteotomy: a case control study, Archives of Orthopaedic and Trauma Surgery, November 2009, 129:1483

[14] Dominique Saragaglia, Numa Mercier, Pierre-Emmanuel Colle, Computer-assisted osteotomies for genu varum deformity: which osteotomy for which varus?, International Orthopaedics, February 2010, Volume 34, Issue 2, pp 185-190.

[15] Louis Solomon, David Warwick, Selvadurai Nayagam, Apley's System of Orthopaedics and Fractures,International Student Edition, Ninth Edition, 2010 pgs. 311-314,692

[16] SS Mohanty,Parag Sanchetil, Clinical Examination of the knee, Textbook of Orthopaedics and Trauma, second edition, 2008, Pgs. 2961-2976 